\title{
A New-Proposal Physical Examination Test for Unilateral Lower Extremity Edema
}

\author{
Fatih Ada, MD, ${ }^{1}$ Volkan Emren, $\mathrm{MD}^{2}$ \\ ${ }^{1}$ Department of Cardiovascular Surgery, Cumhuriyet University School of Medicine, Sivas, Turkey; ${ }^{2}$ Department of \\ Cardiology, İzmir Katip Çelebi University School of Medicine, Izmir, Turkey
}

\section{ABSTRACT}

Objective: Patients with iliac vein compression syndrome (IVCS) usually present to the hospital with left-sided leg edema. We looked for an answer to the question: "Can iliac vein compression syndrome (IVCS) be predicted with a reliable physical examination test in the differential diagnosis?"

Methods: We tested a new physical examination on patients with only left-sided lower extremity edema. In this physical examination the widest area of the calf point (just below tuberosity of the tibia) and medial malleolus was measured in both legs on the Trendelenburg position at $30^{\circ}$ and repeated in standing position. Then the iliac venography was performed.

Results: The test was performed on $32(\mathrm{~N}=32)$ patients with left extremity edema. IVCS was observed on $18(\mathrm{n}=18)$ (56\%) patients. The test was found to have $88 \%$ sensitivity and $92 \%$ specificity in IVCS.

Conclusion: This new physical examination finding, which may be valuable in diagnosing IVCS, is proposed for use in patients with unilateral left-sided edema to preclude unnecessary use of expensive diagnostic imaging methods.

\section{INTRODUCTION}

The iliac vein compression syndrome (IVCS) is actually much more common than thought in the general population. According to the study of May and Thurner, which was conducted on cadavers 60 years ago, the rate of the left common iliac vein spur was 22\% (May 1957). Many patients with IVCS are misdiagnosed with classic venous insufficiency and undergo operation. On the other hand, many patients, though having symptoms like unilateral extremity edema, continue to live without any treatment because venous insufficiency cannot be detected. IVCS can cause major complications such as deep vein thrombosis (DVT) and pulmonary thromboembolism (PTE) (Mousa 2013). Some of the patients were diagnosed with these complications, or these complications could be misdiagnosed without detecting the underlying IVCS. Therefore, a simple, practical

Received March 30, 2018; accepted August 2, 2018.

Correspondence: Fatih Ada, Assistant Professor, Cumburiyet University School of Medicine, Department of Cardiovascular Surgery, Kayseri - Sivas Yolu, Cumburiyet Universitesi, Postal Code: 58140, Merkez, Sivas, Turkey; +90-346219-10-10; fax: +90-346-219-11-10 (e-mail: drfatihada@gmail.com). diagnostic test is needed to easily diagnose IVCS before complications occur and eliminate further unnecessary use of expensive imaging tests. Nowadays, as in all disciplines in clinical practice, physical examination is neglected with the development and widespread use of imaging and laboratory technology in cardiovascular diseases (Mohammed 2016). Under these circumstances, in this study we aim to investigate the diagnostic accuracy of a new physical examination for IVCS (May-Thurner syndrome) in patients with unilateral left lower extremity edema.

\section{METHODS}

In this observational and cross-sectional study, we included $32(\mathrm{~N}=32)$ patients with left leg edema who applied to the cardiovascular surgery clinic of Sivas Numune Hospital between December 2016 and October 2017.A written consent form was obtained from all patients. We performed the physical examination by measuring leg circumference, just above the medial malleolus and on the tuberosity of the tibia at the neutral position in the standing position, and the test was repeated at the $30^{\circ}$ Trendelenburg position. After physical examination, left iliac venography, which is the gold standard diagnostic method for IVCS, was performed on all patients. Venography results were compared with preintervention measurements.

\section{Including Criteria}

Patients were included if the difference in circumference in the left extremity relative to the right extremity is $\geq 1 \mathrm{~cm}$ on the medial malleolus or $\geq 2$ on the tuberosity of the tibia (on the calf) (Bickley 2013).

\section{Exclusion Criteria}

Patients with bilateral lower extremity edema, known lymphedema, known DVT history, presence of acute, subacute, or chronic DVT in the Doppler ultrasound, splint edema in extremities due to limb fracture, congenital unilateral extremity hypertrophy, or atrophy were excluded.

\section{Performing the Test}

Following routine anamnesis and classical vascular examination, considering the symptoms of each patient, we measured both the widest part of the calf (just below the other tuberosity of the tibia) and just below the medial malleolus 


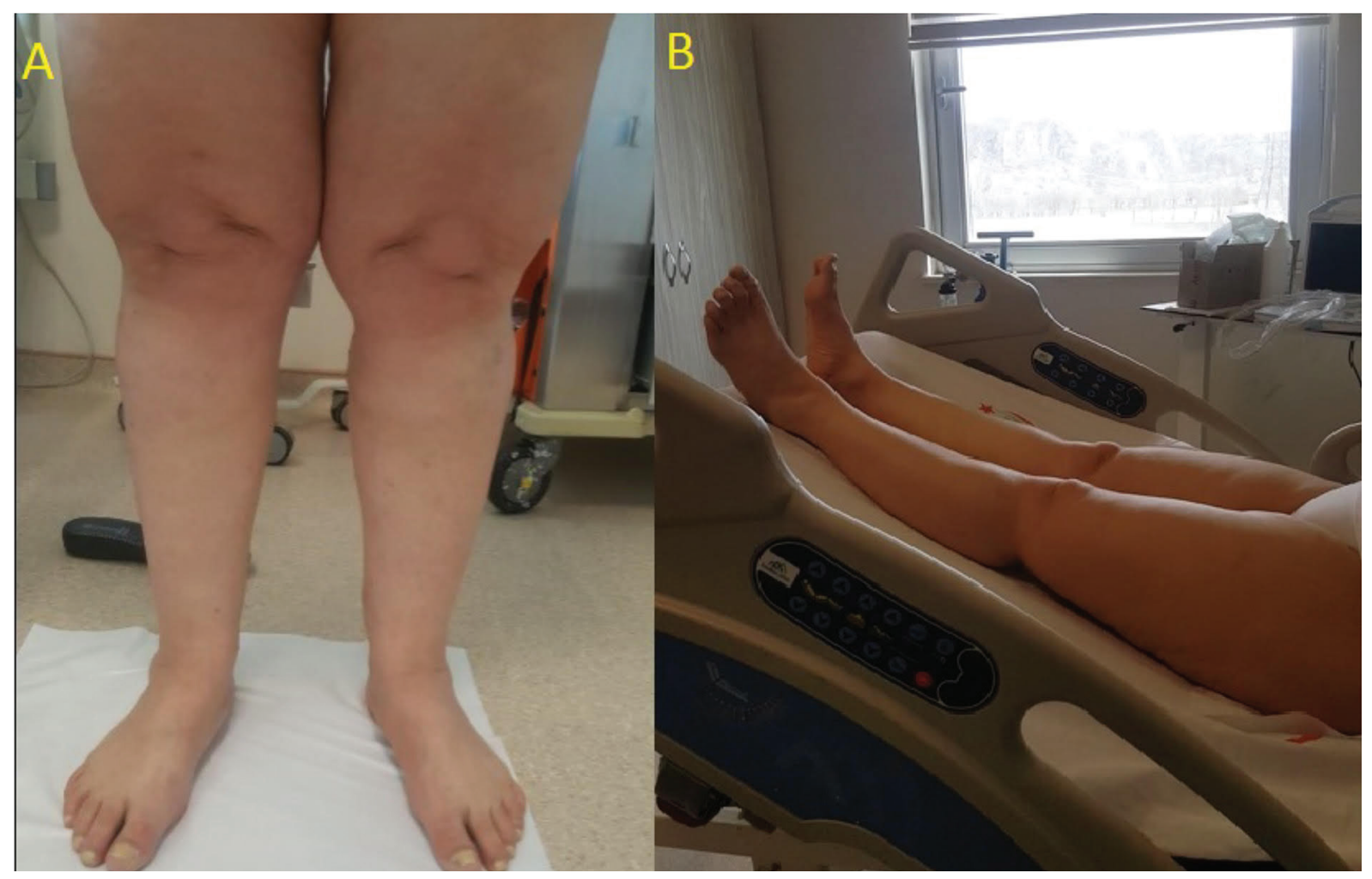

Figure 1. (A) Standing neutral position. (B) Trendelenburg position at $30^{\circ}$.

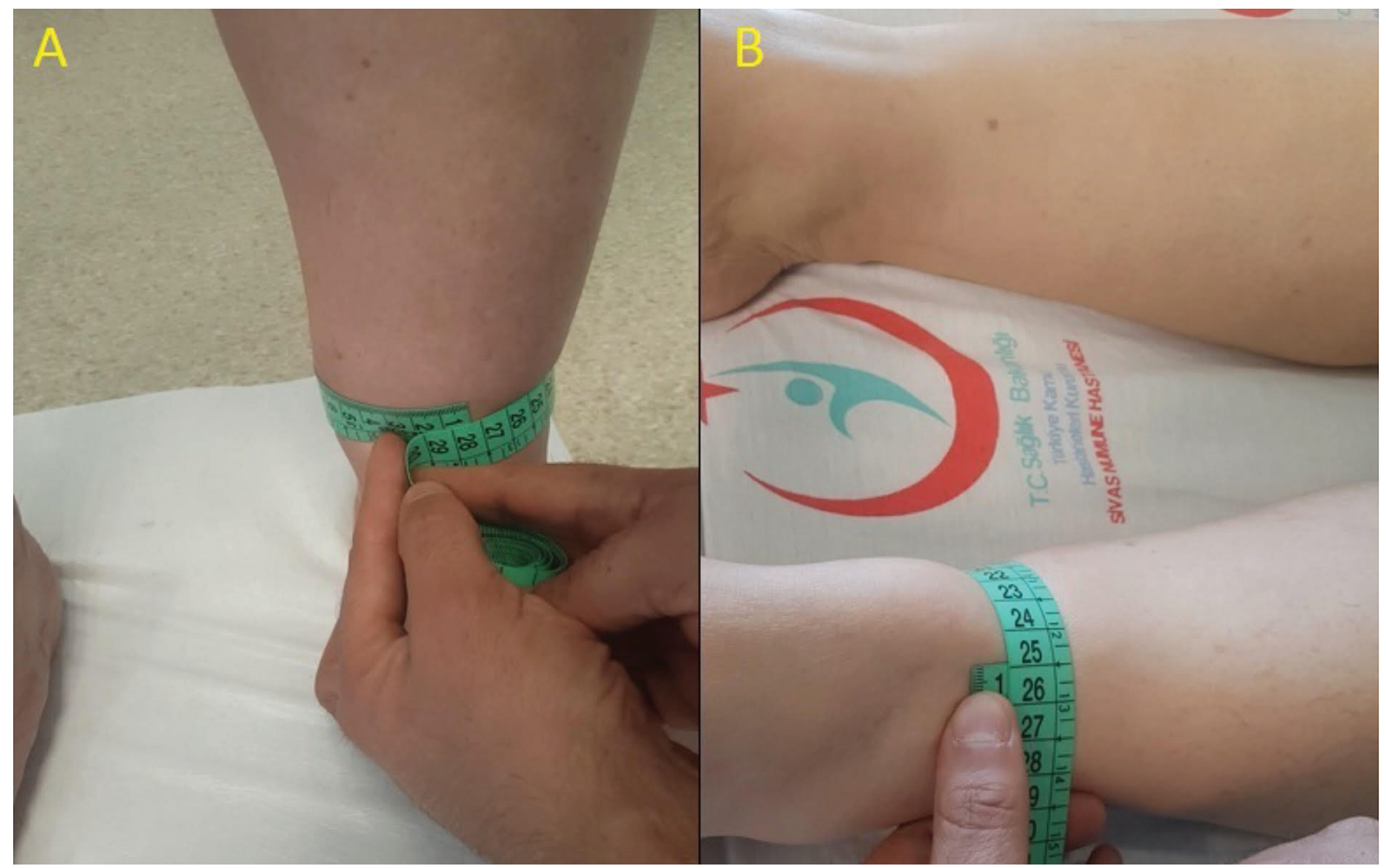

Figure 2.(A) Ankle circumference measurement on the standing neutral position. Note that the measurement is $27.5 \mathrm{~cm}$. (B) Ankle circumference measurement on the Trendelenburg position at $30^{\circ}$. Note that the measurement is $24.8 \mathrm{~cm}$. 
Table 1. Measurement Data of the Test

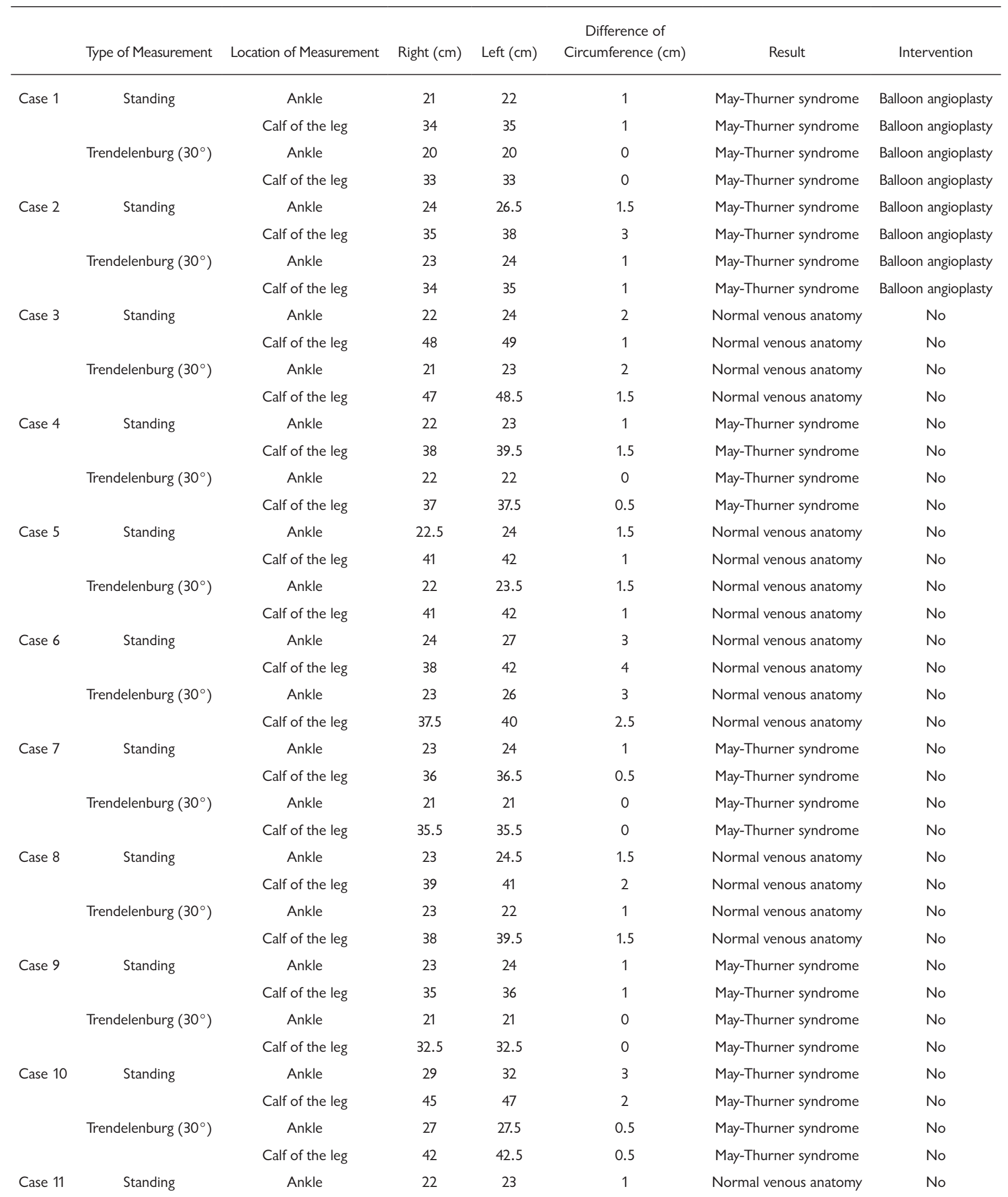


Table 1. Measurement Data of the Test (continued)

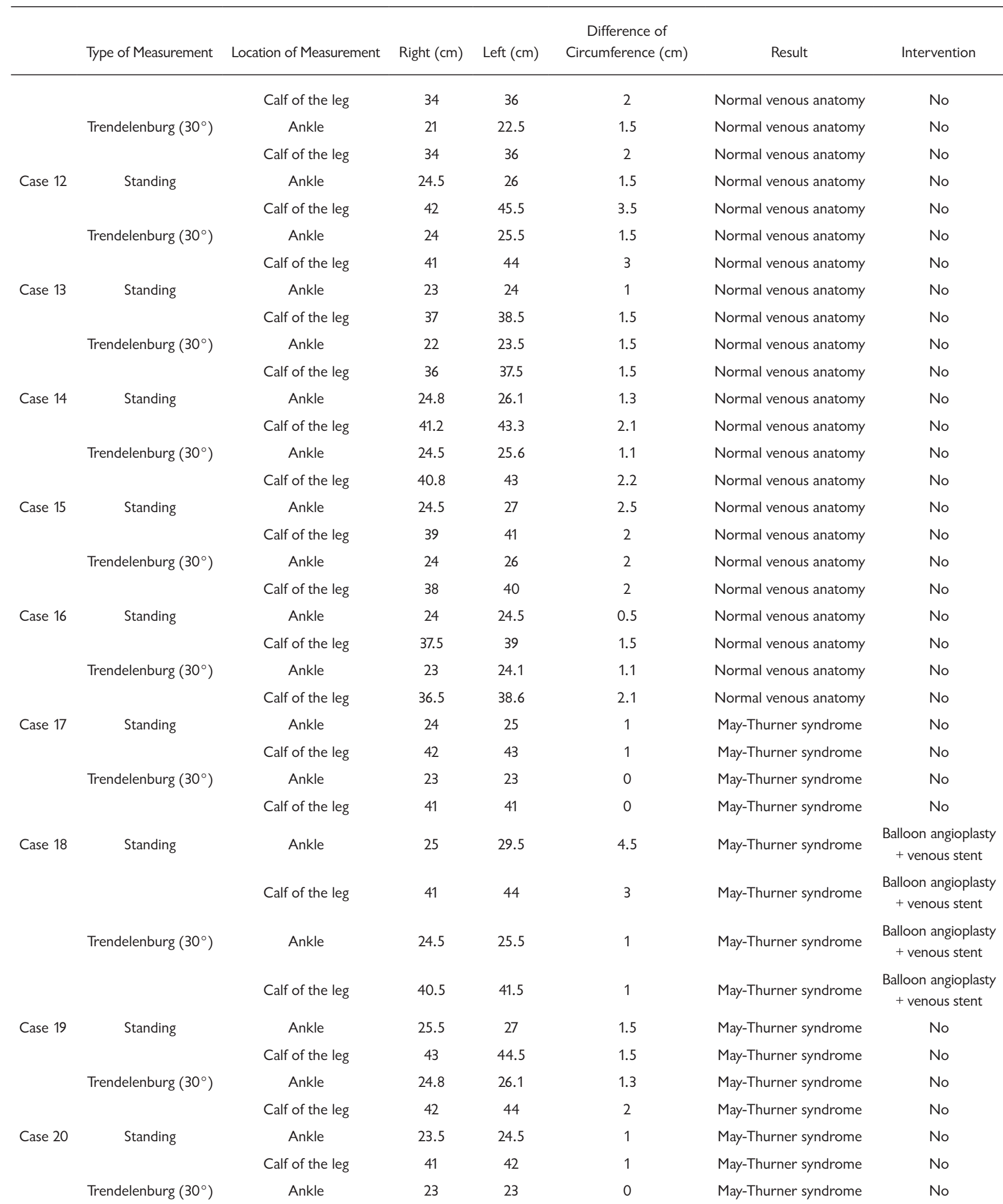


Table 1. Measurement Data of the Test (continued)

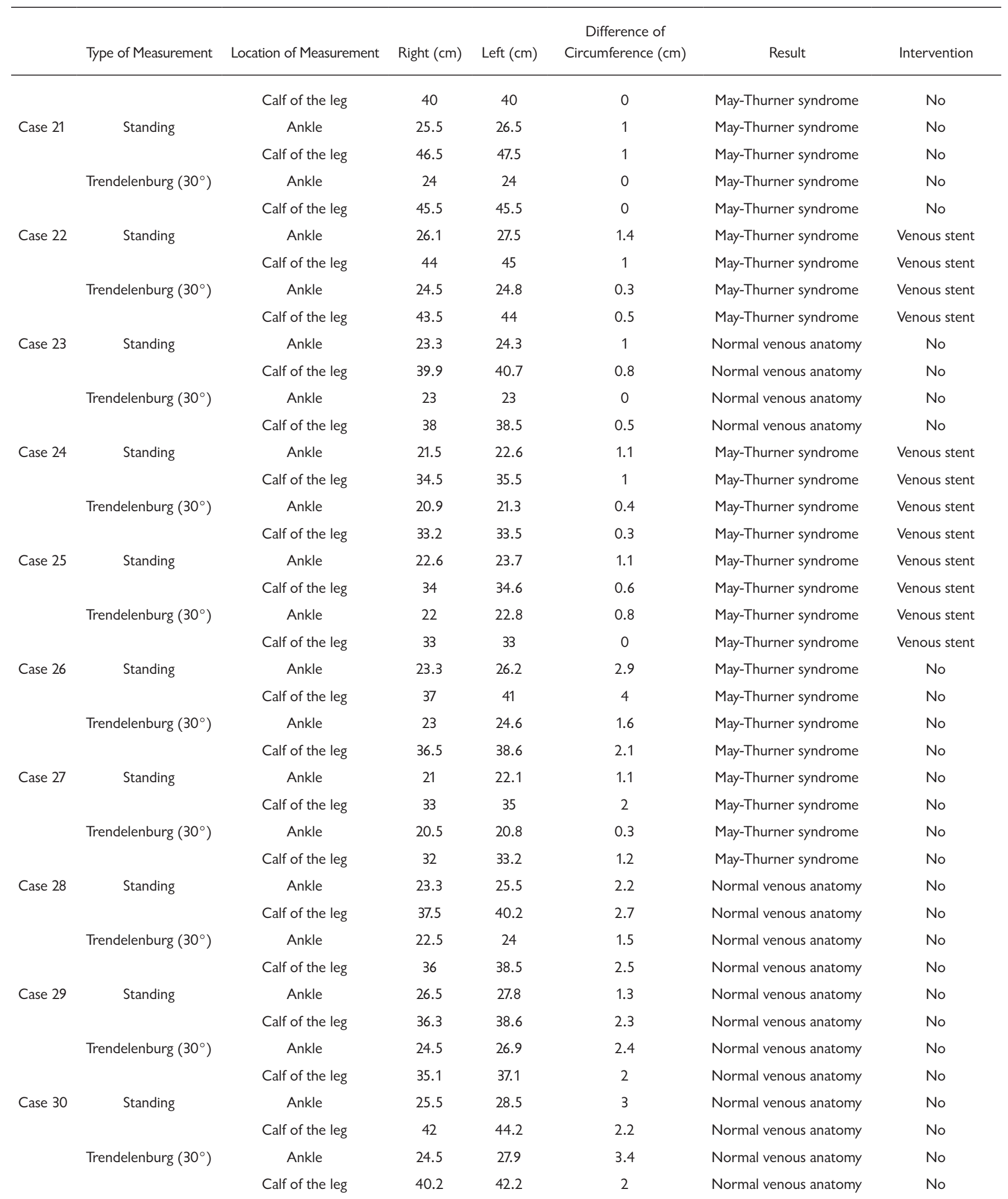


Table 1. Measurement Data of the Test (continued)

\begin{tabular}{|c|c|c|c|c|c|c|c|}
\hline & Type of Measurement & Location of Measurement & Right $(\mathrm{cm})$ & Left $(\mathrm{cm})$ & $\begin{array}{c}\text { Difference of } \\
\text { Circumference }(\mathrm{cm})\end{array}$ & Result & Intervention \\
\hline \multirow{2}{*}{ Case 31} & & Calf of the leg & 36.1 & 37.4 & 1.3 & May-Thurner syndrome & No \\
\hline & Trendelenburg $\left(30^{\circ}\right)$ & Ankle & 24.1 & 24.3 & 0.2 & May-Thurner syndrome & No \\
\hline \multirow{3}{*}{ Case 32} & & Calf of the leg & 35 & 36.4 & 1.4 & May-Thurner syndrome & No \\
\hline & Trendelenburg $\left(30^{\circ}\right)$ & Ankle & 23 & 23.2 & 0.2 & May-Thurner syndrome & No \\
\hline & & Calf of the leg & 34.5 & 34.8 & 0.3 & May-Thurner syndrome & No \\
\hline
\end{tabular}

with a plastic, nonstretch, flexible, disposable tape. A total of 4 points on both legs were measured. We performed the test if there was a difference of $1 \mathrm{~cm}$ or more on the medial malleolus or $2 \mathrm{~cm}$ or more on the tuberosity of the tibia at the first measurement.

The barefoot patient was kept in an upright standing position for 10 minutes, faced across the room, and only wore underwear; and the distance between the legs was sufficient for measurement. Medial malleolus and the tuberosity of the tibia were identified and the circumference of both legs was measured (Figure 1). Subsequently, the patient was taken to the examination stretcher for 10 minutes, waiting with no motion and facing the ceiling, and with his/her feet up (at $30^{\circ}$ in the Trendelenburg position), the measurements were taken and noted again (Figure 2).

As we mentioned above, the difference in circumference in the left extremity relative to the right extremity $\geq 1 \mathrm{~cm}$ on the medial malleolus or $\geq 2 \mathrm{~cm}$ on the tuberosity of the tibia (on the calf) was considered to be significant. The test was followed by positioning at the Trendelenburg position; if the difference in leg circumferences was $\leq 1 \mathrm{~cm}$ on the medial malleolus or $\leq 2 \mathrm{~cm}$ on the calf, the test was considered positive. However, the test was considered negative, if the difference was $>1 \mathrm{~cm}$ on the medial malleolus and $>2$ $\mathrm{cm}$ on the calf or if the difference in the first measurement or the second measurement was considered to be the same or greater.

\section{Statistical Analyses}

All analyses were performed by using IBM SPSS Statistics for Windows, Version 19.0. (IBM Corp., Armonk, NY, USA). Numerical variables are presented as mean \pm standard deviation and nominals as percentages. All variables were subjected to Kolmogorov-Smirnov testing to determine whether they were normally distributed. Nonparametric values were compared by using the Mann-Whitney $U$ test. The chi-square and Fischer exact tests were used to compare categorical data. We also calculated the sensitivity and specificity, the positive and negative predictive values of physical examination for the determining of IVCS. A $P$ value $<.05$ was considered significant.

\section{RESULTS}

The test was conducted on 32 patients who met the appropriate criteria. IVCS syndrome was seen in $18(56 \%)$ of the patients. Twelve patients (66.7\%) were female and $6(33.3 \%)$ were male. Two patients had a negative test but were diagnosed with IVCS syndrome (Table 1). The test was positive in one patient and was not diagnosed with IVCS.

There was no saphenofemoral or deep venous insufficiency on the left lower extremity with venous Doppler ultrasonography in $8(44.5 \%)$ patients with IVCS, and $3(16.6 \%)$ patients had left lower extremity varicose vein surgery history. No varicose veins were observed on physical examination in $10(55.6 \%)$ patients diagnosed with IVCS. The demographic data of the patients are shown in Table 2. Data on the reliability of the test are shown in Table 3 .

Six patients $(33.3 \%)$ diagnosed with IVCS underwent interventional treatment. Balloon-only angioplasty was performed in $2(11.1 \%)$ patients, balloon angioplasty with venous stent was performed in $1(5.5 \%)$ patient, and direct venous stent treatment was performed in $3(16.6 \%)$ patients. The other $12(66.7 \%)$ patients were treated with a venotonic agent, antiplatelet drugs, and compression stockings. These patients were followed up with medicine because they did not accept balloon angioplasty or venous stent after diagnosis (Table 4).

\section{DISCUSSION}

IVCS is a mechanical compression of the left common iliac vein between the right main iliac artery and the lumbar corpus vertebrae. Internal luminal intimal hyperplasia developed as a secondary to mechanical compression, and arterial pulsation leads to "spur" development in the obstructed area. These pathophysiologic factors ultimately result in varicose enlargement and pelvic collateral development in the proximal part of the obstruction (May 1956). The tendency to develop venous thrombosis is increased. Previous studies showed that the left iliac DVT is 2 times diagnosed more than the right iliac DVT (Boyd 2004).

Our physical examination is developed according to the 
Table 2. The Demographic Data of the Patients*

\begin{tabular}{|c|c|c|c|c|c|c|c|c|c|}
\hline Case 2 & Male & 174 & 78 & 25.8 & Yes & No & Grade 4 SFI, no DVI & IVCS & Positive \\
\hline Case 3 & Female & 162 & 98 & 37.3 & No & No & Grade 4 SFI, no DVI & NVA & Negative \\
\hline Case 6 & Female & 158 & 89 & 35.7 & No & No & Grade 4 SFI, no DVI & NVA & Negative \\
\hline Case 7 & Male & 170 & 73 & 25.3 & Yes & No & Grade 2 SFI, no DVI & IVCS & Positive \\
\hline Case 8 & Female & 157 & 90 & 36.5 & No & No & Grade 2 SFI, no DVI & NVA & Negative \\
\hline Case 9 & Female & 158 & 69 & 27.6 & No & No & Grade 2 DVI, no SFI & IVCS & Positive \\
\hline Case 13 & Female & 160 & 74 & 28.9 & Yes & No & Grade 2 SFI, no DVI & NVA & Negative \\
\hline Case 14 & Female & 170 & 90 & 31.1 & Yes & No & Grade $1 \mathrm{SFI}$, no DVI & NVA & Negative \\
\hline Case 15 & Female & 160 & 85 & 33.2 & No & No & No DVI or SFI & NVA & Negative \\
\hline Case 16 & Male & 187 & 96 & 27.5 & Yes & Yes & Grade $3 \mathrm{SFI}$, no DVI & NVA & Negative \\
\hline Case 17 & Male & 165 & 89 & 32.7 & Yes & No & No DVI or SFI & IVCS & Positive \\
\hline Case 18 & Female & 160 & 85 & 33.2 & No & No & Grade 2 SFI, no DVI & IVCS & Positive \\
\hline Case 19 & Female & 162 & 86 & 32.8 & No & No & No DVI or SFI & IVCS & Negative \\
\hline Case 20 & Female & 152 & 70 & 30.3 & No & Yes & No saphenous vein and no DVI & IVCS & Positive \\
\hline Case 21 & Female & 162 & 95 & 36.2 & No & No & No DVI or SFI & IVCS & Positive \\
\hline Case 28 & Male & 178 & 95 & 30 & Yes & No & Grade $3 \mathrm{SFI}$ and grade $2 \mathrm{DVI}$ & NVA & Negative \\
\hline Case 29 & Female & 160 & 78 & 30.5 & Yes & No & Grade 3 DVI, no SFI & NVA & Negative \\
\hline Case 30 & Female & 178 & 91 & 28.7 & Yes & Yes & Grade 3 DVI, no saphenous vein & NVA & Negative \\
\hline Case 31 & Female & 162 & 58 & 22.1 & No & No & No DVI or SFI & IVCS & Positive \\
\hline Case 32 & Male & 174 & 74 & 24.4 & Yes & No & Grade $1 \mathrm{SFI}$, no DVI & IVCS & Positive \\
\hline
\end{tabular}

*BMI, Body mass index; USG, ultrasonography; DVI, deep venous insufficiency; SFI, saphenofemoral insufficiency; IVCS, iliac vein compression syndrome; NVA, normal venous anatomy.

same hypothesis including the nonvalvular collateral veins that develop secondary to iliac veins' compression from the outside, spurs formation inside, and the Bernoulli principle. Venous obstruction in the iliac vein and backflow from the collateral veins cause venous hypertension in the left leg when the patient is standing, and venous structures dilated in years. When the patient raises his or her feet upward, the flow velocity and hence the flow rates of these collaterals due to the gravity effect are increased, and the venous hypertension in the lower limbs is reduced. Based on the above-mentioned theory, equal circumference or convergence between the right and left lower extremity veins in the Trendelenburg position can be explained provided that fibrin accumulation does not occur because of chronic 
Table 3. The Diagnostic Value Results of the Physical Examination Test* $†$

\begin{tabular}{lccc}
\hline \multicolumn{2}{c}{ Results } & \\
& Disease Present & Disease Absent & Totals \\
\hline Results of diagnostic physical examination test & & \\
Test positive & 16 & 1 & 17 \\
Test negative & 2 & 13 & 15 \\
Totals & 18 & 14 & 32 \\
\hline
\end{tabular}

*All data are $\mathrm{n}$ or $\mathrm{N}(\mathrm{N}=32)$.

$\dagger$ Sensitivity $=0.88$; specificity $=0.92$; positive predictive value $=0.94$; negative predictive value $=0.86$; Pretest probability $($ prevalence $)=0.56$; accuracy $=0.90$; likelihood ratio for a positive test result $=11$; likelihood ratio for a negative test result $=0.02$.

venous insufficiency.

Leg-circumference differences in chronic venous insufficiency are explained by chronic fibrin and collagen accumulation (Eberhardt 2005). Collagen accumulation and fibrin cause a difference in leg circumference if there is a unilateral venous insufficiency. However, because collagen accumulation and fibrin cannot theoretically displace the position, we do not expect the test to be positive in these patients. In addition, this test loses validity in patients with both IVCS and chronic venous insufficiency coexisting with molecular changes. It is obvious that the test will be negative in these patients.

In this instance, confirming the diagnosis with MR angiography or CT angiography or venography is directly related to the experience and clinical suppositions of the physician. In patients with IVCS, if concomitant chronic venous insufficiency does not occur, or occurs without affecting a large area, the test will be expected to be positive. We did not perform venous computed tomography or magnetic resonance angiography in patients with IVCS because of the diagnostic uncertainty and expensiveness of those tests. In addition, venography as a gold standard diagnostic test for IVCS makes a diagnosis clear at a point that there is no room for doubt (Hurst 2001).

In general, the complaints of the patients were pain and swelling of the left leg; and, interestingly, pain mainly occurs at the heel. All of the patients were seen in many different centers and followed by many different doctors from varied disciplines. Patients who were misdiagnosed with chronic venous insufficiency were treated with both medical treatment and compression stockings; some of them were operated on for venous insufficiency. Doppler ultrasonography showed no saphenofemoral insufficiency or deep venous insufficiency in some of the patients.

The physical examination test used in this study is based on very simple methods. In addition to the circumference of the leg, there are many techniques that measure leg volume (Guex 2000). Methods such as water displacement, perometer, disc method, and frustum method can be applied to this test.

The diagnostic accuracy of this physical examination is not
Table 4. The Demographic Data of the Patients and Test Results*

\begin{tabular}{|c|c|c|c|}
\hline & $\operatorname{IVCS}(n=18) \dagger$ & $\operatorname{NVA}(n=14) \dagger$ & $P$ \\
\hline Age, mean \pm SD (range) & $\begin{array}{c}36.83 \pm 8.26 \\
(25-51)\end{array}$ & $\begin{array}{c}42.5 \pm 11.69 \\
(30-67)\end{array}$ & .165 \\
\hline \multicolumn{4}{|l|}{ Sex } \\
\hline Male & $6(33.3 \%)$ & $4(28.5 \%)$ & .773 \\
\hline Female & $12(66.7 \%)$ & $10(71.5 \%)$ & .773 \\
\hline Hypertension & $2(11.1 \%)$ & $5(35.7 \%)$ & .195 \\
\hline Diabetes & $2(11.1 \%)$ & $2(14.2 \%)$ & 1 \\
\hline Smoking & $8(44.4 \%)$ & $4(28.5 \%)$ & .358 \\
\hline $\mathrm{BMI}, \mathrm{kg} / \mathrm{m}^{2} \pm \mathrm{SD}$ & $28.02 \pm 5.05$ & $31.72 \pm 4.32$ & .095 \\
\hline Varicose veins & $8(44.4 \%)$ & $8(57.1 \%)$ & .476 \\
\hline Previous varicose vein surgery & $3(16.6 \%)$ & $2(14.2 \%)$ & 1 \\
\hline Previous medical treatment & $16(88.8 \%)$ & $13(92.8 \%)$ & 1 \\
\hline $\begin{array}{l}\text { Previous compression stocking } \\
\text { treatment }\end{array}$ & $15(83.3 \%)$ & $13(92.8 \%)$ & .613 \\
\hline $\begin{array}{l}\text { Venous insufficiency in Doppler } \\
\text { ultrasonography }\end{array}$ & $10(55.5 \%)$ & $12(85.7 \%)$ & .124 \\
\hline \multicolumn{4}{|l|}{ Physical examination test } \\
\hline Positive & $16(88.9 \%)$ & $\begin{array}{c}\text { Positive, } 1 \\
\text { (7.1\%) }\end{array}$ & $<.001$ \\
\hline Negative & $2(11.1 \%)$ & $\begin{array}{c}\text { Negative, } 13 \\
(92.8 \%)\end{array}$ & $<.001$ \\
\hline Venous stent implantation & $4(22.2 \%)$ & 0 & - \\
\hline Venous angioplasty & $3(16.6 \%)$ & 0 & - \\
\hline
\end{tabular}

*IVCS, iliac vein compression syndrome; NVA, normal venous anatomy; BMI, Body mass index.

†Data aregiven as $\mathrm{n}(\%)$ except for age and BMI, for which the information is in the left column.

$100 \%$; many other physical examination tests also do not have $100 \%$ accuracy. However, the feasibility of this test suggests that the results of the patients to whom the test was applied can be used in clinical practice.

Parameters such as test-related measurement locations, measurement format, and duration will be optimized with studies with large populations.

\section{CONCLUSION}

The new physical examination test is practical, easy, feasible, and cost-effective for the differential diagnosis of IVCS. Thus, many patients will be diagnosed and treated without delayed diagnosis and without complications. However, prospective studies with large populations are needed to able to confirm the specificity and sensitivity of the test. 


\section{ACKNOWLEDGMENTS}

This research received no specific grant from any funding agency in the public, commercial, or not-for-profit sectors. The authors declare no conflict of interest in preparing this article.

\section{REFERENCES}

Bickley LS, Szilagyi PG. Bates' guide to physical examination and history-taking. 11th ed. Philadelphia: Wolters Kluwer Health/Lippincott Williams \& Wilkins; c2013.

Boyd DA. 2004. Unilateral lower extremity edema in May-Thurner syndrome. Mil Med 169(12):968-71.

Eberhardt RT, Raffetto JD. 2005. Chronic venous insufficiency. Circulation 111(18):2398-409.
Guex JJ, Perrin M. 2000. Edema and leg volume: methods of assessment. Angiology 51(1): 9-12.

Hurst DR, Forauer AR, Blooem JR, Greenfield LJ, Wakefield TW, Williams DM. 2001. Diagnosis and endovascular treatment of iliocaval compression syndrome. J Vasc Surg 34(1):106-13.

May R, Thurner J. 1956. [A vascular spur in the vena iliaca communis sinistra as a cause of predominantly left-sided thrombosis of the pelvic veins]. Z Kreislaufforsch 45(23-24):912-22. German.

May R, Thurner J. 1957. The cause of the predominantly sinistral occurrence of thrombosis of the pelvic veins. Angiology 8(5):419-27.

Mohammed KA. 2016. Clinical examination nowadays. Lancet 388(10044):559-60.

Mousa AY, AbuRahma AF. 2013. May-Thurner syndrome: update and review. Ann Vasc Surg 27(7):984-95. 